\title{
Bio-oil production using residual sewage sludge after lipid and carbohydrate extraction
}

\author{
Pansuwan Supaporn', Hoang Vu Ly², Seung-Soo Kim², Sung Ho Yeom ${ }^{1+}$ \\ ${ }^{1}$ Department of Biochemical Engineering, Gangneung-Wonju National University, Gangneung 25457, Republic of Korea \\ ${ }^{2}$ Department of Chemical Engineering, Kangwon National University, Samcheok 25913, Republic of Korea
}

\begin{abstract}
In order to maximize the utilization of sewage sludge, a waste from wastewater treatment facility, the residual sewage sludge generated after lipid and carbohydrate extraction for biodiesel and bioethanol production was used to produce bio-oil by pyrolysis. Thermogravimetric analysis showed that sludge pyrolysis mainly occurred between 200 and $550^{\circ} \mathrm{C}$ (with peaks formed around 337.0 and $379.3^{\circ} \mathrm{C}$ ) with the decomposition of the main components (carbohydrate, lipid, and protein). Bio-oil was produced using a micro-tubing reactor, and its yield (wt $\%$, g-bio-oil/g-residual sewage sludge) increased with an increase in the reaction temperature and time. The maximum bio-oil yield of $33.3 \%$ was obtained after pyrolysis at $390^{\circ} \mathrm{C}$ for $5 \mathrm{~min}$, where the largest amount of energy was introduced into the reactor to break the bonds of organic compounds in the sludge. The main components of bio-oil were found to be trans-2-pentenoic acid and 2-methyl-2-pentenoic acid with the highest selectivity of $28.4 \%$ and $12.3 \%$, respectively. The kinetic rate constants indicated that the predominant reaction pathway was sewage sludge to bio-oil $\left(0.1054\right.$ min $\left.^{-1}\right)$, and subsequently to gas $\left(0.0541 \mathrm{~min}^{-1}\right)$, rather than the direct conversion of sewage sludge to gas $\left(0.0318 \mathrm{~min}^{-1}\right)$.
\end{abstract}

Keywords: Bio-oil, Kinetic analysis, Micro-tubing reactor, Pyrolysis, Residual sewage sludge, Thermogravimetric analysis

\section{Introduction}

There is an increasing demand for alternative liquid fuels due to a shortage of fossil fuels, environmental pollution, and large greenhouse gas emissions. Many biomass conversion methods such as pyrolysis, transesterification, and hydrothermal liquefaction have been developed to produce alternative liquid fuels [1]. Municipal wastewater treatment plants in the USA produce over 6.2 million tons of dried sewage sludge every year [2]; the annual production of sewage sludge in Korea was 4 million tons in 2013, and is expected to increase to 5.4 million tons in 2025 [3]. The disposal of sewage sludge in Korea, highly populated and has suffered from limited landfill sites, was previously heavily dependent on ocean dumping $(61.6 \%$ of the total sewage sludge generated in 2011). However, this was prohibited after 2012 by the London Convention '96 protocol [4]. Nowadays, the most common processes for disposal of sludge include landfilling, agricultural application, and incineration [5]. The above processes are becoming increasingly difficult to operate, because of land-related limitations and increased restrictive regulations [5]. Therefore, other processes that are more economical and respectful of the environment need to be developed. Alternatively, a novel process that converts sewage sludge to valuable chemicals with minimizing final waste would be a promising solution in the treatment of sewage sludge.

Sewage sludge consists of proteins, carbohydrates, and lipids [6], which can be converted to fuels such as biodiesel [2, 6], bioethanol, and bio-oil [5-8] by transesterification, fermentation, and pyrolysis, respectively. Pyrolysis has increasingly been receiving attention in recent years as an acceptable route for waste disposal [9]. Sewage sludge pyrolysis produces three fractions: liquid, solid, and gaseous [10]. The gaseous and liquid fractions had a relatively high-energy value and consequently, they could be considered potential fuels. The solid fraction can be used as cheaper carbon-based adsorbents for pollutant removal [10].

$\mathrm{Li}$ et al. [7] studied the pyrolysis characteristics and kinetics of municipal sludge by Thermogravimetry Fourier-transform infrared analysis (TG-FTIR). The results indicated that the pyrolysis of municipal sludge with nitrogen as the carrier gas could be divided into three stages including dehydration, degradation of organic
This is an Open Access article distributed under the terms of the Creative Commons Attribution Non-Commercial License (http://creativecommons.org/licenses/by-nc/3.0/) which permits unrestricted non-commercial use, distribution, and reproduction in any medium, provided the original work is properly cited.

Copyright (C) 2019 Korean Society of Environmental Engineers
Received November 13, 2017 Accepted July 15, 2018

${ }^{\dagger}$ Corresponding author

Email: shyeom@gwnu.ac.kr

Tel: +82-33-640-2406 Fax: +82-33-641-2410

ORCID: 0000-0002-9851-6069 
matter, and decomposition of inorganic minerals and undecomposed organic matter when the rate of heating was $15^{\circ} \mathrm{C} / \mathrm{min}$. In addition, $\mathrm{CO}_{2}, \mathrm{CO}, \mathrm{CH}_{4}$, some aldehydes, and carboxylic acids were the major gas products of pyrolysis. Pokorna et al. [11] evaluated the production of pyrolysis oil from three types of sewage sludges. The maximum oil yield from flash pyrolysis, performed at $500^{\circ} \mathrm{C}$, was $43.1 \%$; the water content in bio-oils obtained from secondary sludge was relatively low, i.e. $10.3 \%$. In addition, Othman et al. [8] studied the pyrolysis of sewage sludge in a tubular micro-reactor under various conditions. The yields of gas, oil, and char during pyrolysis were in the range of $6.1-14.5 \%, 11.1-32.4 \%$, and 53.1-82.7\%, respectively. The yield of oil increased with an increase in the temperature and reaction time used for pyrolysis. The char, the final residue after pyrolysis, can be considered as an environmentally-friendly source of carbon for preparation of activated carbon, which it is one of the prominent adsorbents with high efficiency for the uptake of pollutants from gas and liquid phase [12]. If the char was modified to nanocomposite, it would be used as a useful adsorbent even in petrochemical industry [13-14].

Previously, we had extracted lipids from sewage sludge for biodiesel production. The efficiency of lipid extraction was $92.9 \%$ [6]. Residual sewage sludge resulting from lipid extraction was subjected to sugar extraction, and more than $90 \%$ of the total carbohydrate content was extracted by acid pretreatment, followed by enzymatic saccharification [15]. Finally, we produced bioethanol using the sugars extracted from sewage sludge [15]. However, because the total content of lipid and carbohydrate is less than $25 \%$ [6], the residual sewage sludge is still of large volume and needs to be utilized to produce valuable materials and minimize the remanent waste that would be landfilled.

As stated above, most previous studies used raw sewage sludge for bio-oil production. In this study, to achieve the maximum utilization of the sewage sludge, the residual sewage sludge that remained after lipid and sugar extraction was used to produce bio-oil through pyrolysis. That is, this study also aimed to minimize the final waste to be treated. The characteristics of sewage sludge pyrolysis after lipid and sugar extraction were investigated. In addition, bio-oil was produced using a micro-tubing reactor, and the optimal conditions for this reaction were explored. Finally, the composition of bio-oil was investigated, and a kinetic study of this pyrolysis reaction was conducted.

\section{Experimental Methods}

\subsection{Sewage Sludge Preparation and Its Characterization}

Sewage sludge was collected from the Gangneung wastewater treatment facility [6]. Previously, we optimized the process of lipid extraction from sewage sludge for biodiesel production [6]. To save on organic solvents, we changed the extraction conditions; lipids were extracted twice from dried sewage sludge by incubating $8 \mathrm{~mL} / \mathrm{g}$-sludge with chloroform (99\%; Wako, Japan) and methanol (99\% purity, Showa, Japan) in a ratio of $1: 2(\mathrm{v} / \mathrm{v})$ for $4 \mathrm{~h}$ at $70^{\circ} \mathrm{C}$. The sewage sludge obtained after lipid extraction was saccharified to obtain sugars for bioethanol production by a treatment with acid $\left(5.9 \%(\mathrm{v} / \mathrm{v})\right.$ at $120^{\circ} \mathrm{C}$ for $\left.85 \mathrm{~min}\right)$, followed by a treatment with $500 \mu \mathrm{L}$ of an enzymatic solution comprised of Celluclast (Novozyme, Denmark) and Viscozyme (Novozyme, Denmark) in

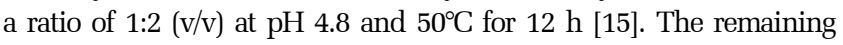
sewage sludge after lipid and sugar extraction was dried at $105^{\circ} \mathrm{C}$ for $24 \mathrm{~h}$ and used to obtain bio-oil by pyrolysis in this study. Carbohydrate content was determined by using the phenol-sulfuric acid method [16]. Crude protein content was determined by the Kjeldahl method using the Kjeldahl system (Buchi, Flawil, Switzerland). The moisture content of the sewage sludge was measured according to ASTM E 1756 [17]. The ash content of sewage sludge was measured according to ASTM E 1755 [17]. The C, H, $\mathrm{N}$, and $\mathrm{S}$ content of sewage sludge were determined using an elemental analyzer (Flash EA1112, CE Instrument, UK), and the O content was estimated by subtracting the sum of $\mathrm{C}, \mathrm{H}, \mathrm{N}$, and S content from 100\% [17-18].

Thermogravimetric analysis (TGA) of the sewage sludge sample (12.0 $\pm 1.0 \mathrm{mg}$ ) was carried out using TGA equipment (Q50 Instrument, New Castle, USA). Nitrogen was used as the carrier gas at a flow rate of $25 \mathrm{~mL} / \mathrm{min}$. The temperature was elevated from 25 to $700^{\circ} \mathrm{C}$ at heating rates of $5,10,15$, and $20^{\circ} \mathrm{C} / \mathrm{min}$. The differential rate of conversion, $d X / d t$, was determined by differentiating the conversion by time at different temperatures and heating rates.

\subsection{Micro-tubing Reactor}

The pyrolysis of the sewage sludge sample was carried out in a micro-tubing reactor that was tightly closed. The body of the apparatus consisted of a stainless-steel reactor that was $110 \mathrm{~mm}$ in length and $22 \mathrm{~mm}$ in diameter. The pyrolysis system (Fig. 1) consisted of a salt bath, temperature controller, mechanical stirrer, and micro-tubing reactor with an inner volume of approximately [18]. In each experiment, the tubing reactor was loaded with 2.0 $\mathrm{g}$ of the sewage sludge sample and placed into a molten salt bath

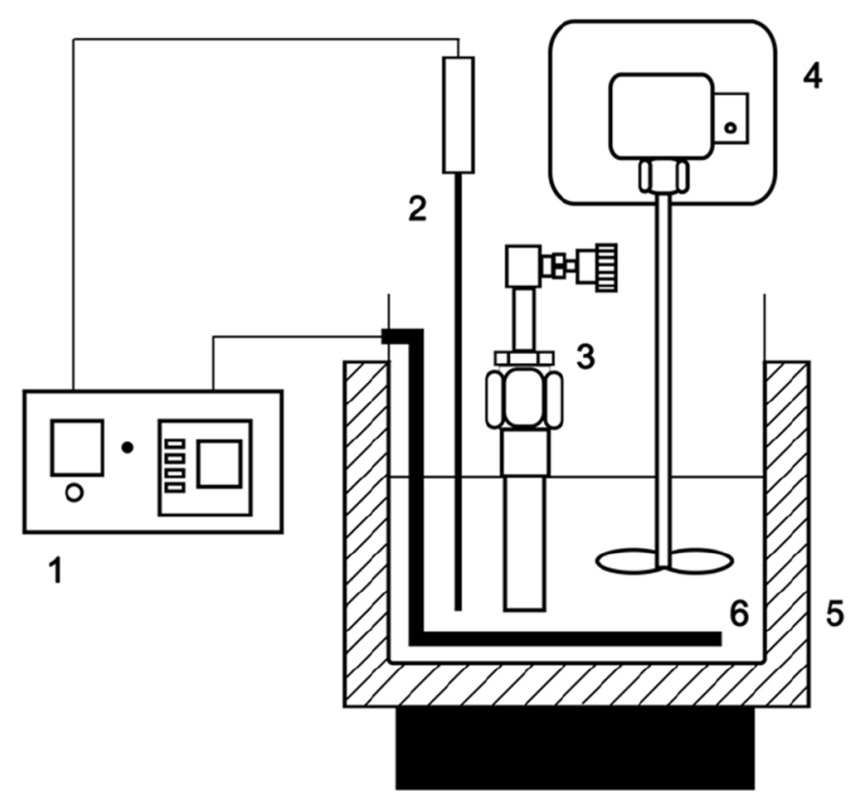

Fig. 1. Schematic diagram of experimental apparatus.

1; Temperature controller, 2; Thermocouple, 3; Micro-tubing reactor, 4; Stirrer, 5; Salt bath, 6; Heater 
$40 \mathrm{~cm}^{3}$. A molten salt bath, which has excellent heat transfer properties, was prepared with eutectic salt of $\mathrm{KNO}_{3}(59 \%)$ and $\mathrm{Ca}\left(\mathrm{NO}_{3}\right)_{2}(41 \%)$ that had been pre-heated to the desired reaction temperature of 370,380 or $390 \pm 1^{\circ} \mathrm{C}$. These pyrolysis temperatures were selected based on data from the differential thermogravimetric analysis (DTG) curve. Various reaction times ranging from 1 to $5 \mathrm{~min}$ were tested at each reaction temperature. After the desired reaction time at the giving temperature was reached, the reactor was immediately removed from the molten salt bath and cooled to the ambient temperature using cold water. After cooling for $60 \mathrm{~min}$, the reactor was opened by removing the valve assembly to release the gas, and the oil and char fractions were collected [19]. The pyrolysis product distribution was determined by weighing the gas, oil and char products. The gas yield was obtained by weighing the micro-tubing reactor before and after the release of gas. The mixture of char and bio-oil were separated into bio-oil (acetone-soluble) and char (acetone-insoluble) using a micro filter paper (pore size: $0.45 \mathrm{um}$ ), with a vacuum pump after solvent extraction with acetone. After separated, the char were dried in an oven at $90^{\circ} \mathrm{C}$ for 60 min and cooled to the ambient temperature in exsiccator. After that, the char yield was obtained by weighing the sample before and after reaction. Each experiment was repeated three times, and the average data were used for estimating yields. The product yields were calculated according to the following equations [18].

$$
\begin{gathered}
\text { Gas yield }(\%)=\frac{\text { gas weight }}{\text { feed weight }} \times 100 \\
\text { Char yield }(\%)=\frac{\text { char weight }}{\text { feed weight }} \times 100 \\
\text { Oil yield }(\%)=100-(\text { gas yield }+ \text { char yield })
\end{gathered}
$$

\subsection{Analysis}

The analysis of bio-oil composition was performed using GC-MS (7890A, Agilent, USA) with a capillary column of HP-5MS (30 m $\times 0.25 \mathrm{~mm} \times 0.25 \mu \mathrm{m})$. Highly pure helium was used as a carrier gas with a flow rate of $1.0 \mathrm{~mL} / \mathrm{min}$. The temperature of the GC injector was kept at $280^{\circ} \mathrm{C}$ and the injection volume was $1 \mu \mathrm{L}$. The GC oven was programmed from an initial temperature of $40^{\circ} \mathrm{C}$ to $200^{\circ} \mathrm{C}$ with a heating rate $5^{\circ} \mathrm{C} / \mathrm{min}$; the temperature was maintained for $5 \mathrm{~min}$, and then increased to $300^{\circ} \mathrm{C}$ at a heating rate of $10^{\circ} \mathrm{C} / \mathrm{min}$. This temperature was maintained for a duration of $5 \mathrm{~min}$ [18].

\subsection{Kinetic Parameter Estimation}

Kinetic parameter estimation was carried out through a nonlinear least-squares regression of the experimental data using Sigma Plot
(Ver.10, Systat software, Inc, USA). The reaction rate constants $k_{1}, k_{2}$, and $k_{3}$ that were obtained for gas, liquid, and solid products at three different reaction temperatures are shown in Table 3.

\section{Results and Discussion}

\subsection{Characterization of Sewage Sludge after Lipid and Sugar Extraction}

The composition of raw sewage sludge (RSS), sludge after lipid extraction (SALE), and sludge after lipid and sugar extraction (SALSE) were measured and compared, as presented in Table 1. RSS consisted of $14.5 \%$ lipids, $8.9 \%$ carbohydrates, $42.8 \%$ proteins, $32.1 \%$ ash, and $1.7 \%$ moisture. After lipid extraction for biodiesel production, the compositions of lipids, carbohydrates, proteins, ash, and moisture were $2.6 \%, 8.9 \%, 52.2 \%, 35.3 \%$, and $1.0 \%$, respectively. Notably, the lipid content was significantly decreased from $14.5 \%$ to $2.6 \%$ while carbohydrates and proteins were barely extracted. The residual sewage sludge was further utilized for sugar extraction using acid pretreatment, followed by enzyme pretreatment for bioethanol production. After lipid and sugar extraction, the residual sewage sludge mainly contained $56.1 \%$ proteins, $2.3 \%$ lipids, $1.0 \%$ carbohydrates, $38.9 \%$ ash, and $1.7 \%$ moisture. To achieve the complete utilization of sewage sludge, SALSE was pyrolyzed to obtain valuable bio-oil.

Table 2 shows that the $\mathrm{C}, \mathrm{H}, \mathrm{O}, \mathrm{N}$, and $\mathrm{S}$ content of SALSE was $47.8 \%, 6.5 \%, 38.7 \%, 5.6 \%$, and $1.5 \%$, respectively. According to the Demirbas method $[18,20]$, the higher heating value (HHV) of biomass could be calculated using the following equation $[8,18]$ :

$$
\begin{aligned}
& \mathrm{HHV}(\mathrm{M} J / \mathrm{kg})= \\
& \{33.5[\mathrm{C}]+142.3[\mathrm{H}]-15.4[\mathrm{O}]-14.5[\mathrm{~N}]\} \times 10^{-2}
\end{aligned}
$$

Here, $[\mathrm{C}],[\mathrm{H}],[\mathrm{O}]$, and $[\mathrm{N}]$ represent the concentrations (wt\%) of carbon, hydrogen, oxygen, and nitrogen, respectively. The HHV is strongly dependent on the carbon and oxygen content of the feedstock; high carbon and low oxygen content result in an increase in the HHV. The HHV of SALSE was $18.51 \mathrm{MJ}$ $\mathrm{kg}^{-1}$, which was $35.7 \%$ and $20.2 \%$ higher than those of sewage sludge in studies by Ma et al. [21] (13.64 $\mathrm{MJ} \mathrm{kg}^{-1}$ ) and Calvo et al. [22] (15.4 MJ kg-1), and higher than that of the microalgae sample (12.11 $\mathrm{MJ} \mathrm{kg}^{-1}$ ) [23], indicating its feasibility as a source of energy [24].

\subsection{Thermogravimetric Analysis of the Sewage Sludge after

\begin{tabular}{|c|c|c|c|c|c|}
\hline Type of sludge & Moisture (\%) & Lipid (\%) & Carbohydrate (\%) & Protein (\%) & Ash (\%) \\
\hline Raw sewage sludge & 1.7 & 14.5 & 8.9 & 42.8 & 32.1 \\
\hline Sludge after lipid extraction & 1.0 & 2.6 & 8.9 & 52.2 & 35.3 \\
\hline Sludge after lipid and carbohydrate extraction & 1.7 & 2.3 & 1.0 & 56.1 & 38.9 \\
\hline
\end{tabular} Lipid and Sugar Extraction}

The TGA of SALSE can be expressed as a function of the conversion factor $X$, which is defined as follows [23-24]:

Table 1. Composition of Sewage Sludge after Lipid and Carbohydrate Extraction 
Table 2. Activation Energy and Pre-exponential Factors for the Pyrolysis of Residual Sewage Sludge after Lipid and Carbohydrate Extraction

\begin{tabular}{lcccccccccc}
\hline & \multicolumn{10}{c}{ Conversion (\%) } \\
\cline { 2 - 11 } & $\mathbf{1 0}$ & $\mathbf{2 0}$ & $\mathbf{3 0}$ & $\mathbf{4 0}$ & $\mathbf{5 0}$ & $\mathbf{6 0}$ & $\mathbf{7 0}$ & $\mathbf{8 0}$ & $\mathbf{9 0}$ \\
\hline Ea $(\mathrm{kJ} / \mathrm{mol})$ & 67.0 & 71.9 & 81.7 & 101.7 & 83.0 & 87.1 & 97.4 & 123.4 & 173.5 \\
Zero order & $4.1 \times 10^{2}$ & $1.5 \times 10^{3}$ & $1.3 \times 10^{4}$ & $3.3 \times 10^{5}$ & $4.3 \times 10^{3}$ & $5.9 \times 10^{3}$ & $1.9 \times 10^{4}$ & $4.8 \times 10^{5}$ & $2.0 \times 10^{8}$ \\
First order & $1.1 \times 10^{2}$ & $2.0 \times 10^{2}$ & $1.1 \times 10^{3}$ & $2.2 \times 10^{4}$ & $2.3 \times 10^{2}$ & $2.7 \times 10^{2}$ & $7.2 \times 10^{2}$ & $1.6 \times 10^{4}$ & $6.2 \times 10^{6}$ \\
Second order & 5.5 & $5.1 \times 10^{-1}$ & $3.3 \times 10^{-1}$ & 1.1 & $2.6 \times 10^{-3}$ & $8.4 \times 10^{-4}$ & $7.3 \times 10^{-4}$ & $6.0 \times 10^{-3}$ & $9.0 \times 10^{-1}$ \\
\hline
\end{tabular}

$$
X=\frac{W_{0}-W}{W_{0}-W_{\infty}}
$$

Here, $W_{0}$ is the initial mass of SALSE, $W$ is the mass of pyrolytic SALSE at time $t$, and $W_{\infty}$ is the final residual mass after TGA. The degree of conversion versus temperature of the sewage sludge in TGA at different heating rates of $5,10,15$, and $20^{\circ} \mathrm{C} / \mathrm{min}$ are
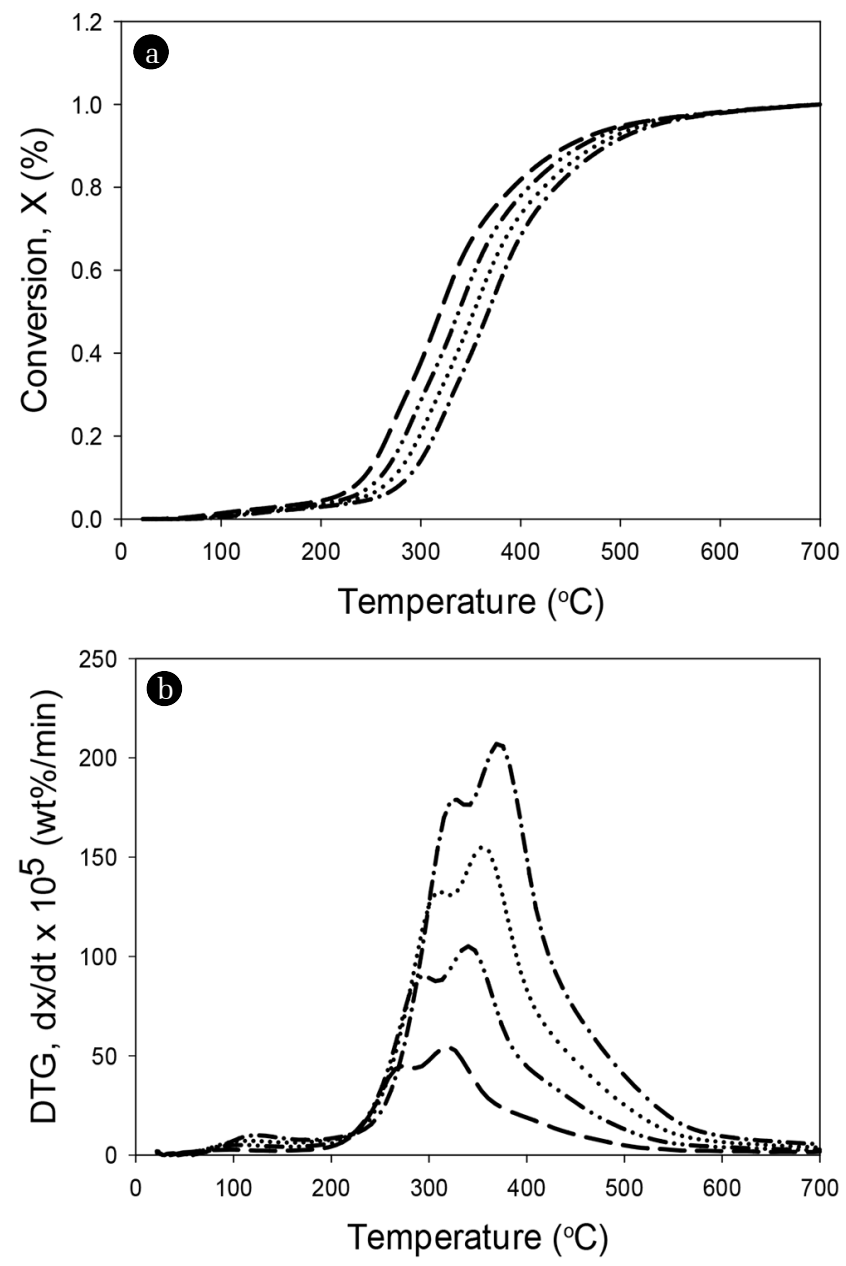

Fig. 2. (a) Thermogravimetric analysis (TCA) and (b) differential thermogravimetric analysis (DTG) curves of sewage sludge after lipid and sugar extraction at different heating rates.

-- -: $5^{\circ} \mathrm{C} / \mathrm{min},-\cdots: 10^{\circ} \mathrm{C} / \mathrm{min}, \cdots: 15^{\circ} \mathrm{C} / \mathrm{min},--: 20^{\circ} \mathrm{C} / \mathrm{min}$ shown in Fig. 2(a). The formation of a peak at a temperature lower than $200^{\circ} \mathrm{C}$ could be attributed to the vaporization of moisture attached to the sample surface [8, 25-26]. However, in this study, a few peaks appeared below $200^{\circ} \mathrm{C}$ because SALSE was well dried, which was consistent with the fact that the moisture content of SALSE was as low as $1.68 \%$. The conversion curves at different heating rates of $5,10,15$, and $20^{\circ} \mathrm{C} / \mathrm{min}$ showed a similar behavior, and the height of the curves started to increase rapidly in the temperature range of 200 to $400^{\circ} \mathrm{C}$. However, the conversion curves were shifted toward the right with an increase in the heating rate, which was because of a higher instantaneous thermal energy introduced into the reaction system at a higher heating rate, resulting in a higher conversion rate [23].

The DTG curves of SALSE at different heating rates are shown in Fig. 2(b). The DTG curve at each heating rate has two peaks between 200 and $550^{\circ} \mathrm{C}$ (peaks were around 337.0 and $379.3^{\circ} \mathrm{C}$ ), indicating the decomposition of the main components (lipids, carbohydrates, and proteins) in the SALSE [27]. The figure shows that the maximum rate of conversion or decomposition tends to increase with an increase in the heating rate, possibly because a high heating rate provides more energy for heat transfer into the sewage samples [28]. The maximum points of the DTG curves occurred at 284, 301,317 , and $334^{\circ} \mathrm{C}$ at the heating rates of $5,10,15$, and $20^{\circ} \mathrm{C} / \mathrm{min}$, respectively. Previous studies report that the peaks between 200 and $350^{\circ} \mathrm{C}$ could be attributed to the decomposition of carbohydrates, lipids, and proteins, while those below $200^{\circ} \mathrm{C}$ could be attributed to the vaporization of water and some very light volatile compounds [25, 27, 29-30].

\subsection{Kinetic Parameters for Pyrolysis of Sewage Sludge after Lipid and Sugar Extraction}

Studies regarding TGA graphs contribute to the enhancement of knowledge of the kinetics of this thermal process, and therefore, to the establishment of the optimal operational conditions for effective utilization of sewage sludge [31]. The TGA graphs were analyzed to determine the Arrhenius parameters (activation energy and pre-exponential factor) of sewage sludge. The activation energy is the minimum energy required to start a reaction, and a reaction with low activation energy takes place more easily than a reaction with high activation energy [32]. The pre-exponential factor, also known as the frequency factor, indicates the number of collisions between two molecules. The differential method was used to determine the kinetic parameters of pyrolysis from the thermogravimetric data [14, 23-24]. The rate of conversion, $d X / d t$, during thermal decomposition is expressed as [28], 


$$
\frac{d X}{d t}=k f(X)
$$

The temperature-dependent reaction rate constant $k$ is expressed by the Arrhenius equation;

$$
k=A \exp \left(-\frac{E_{a}}{R T}\right)
$$

Here, $A, E a, R$, and $T$ represent the pre-exponential factor, activation energy, universal gas constant, and temperature, respectively. The temperature-independent conversion function, $f(x)$, is expressed as,

$$
f(X)=X^{n}
$$

Substituting Eq. (7) and (8) into Eq. (6) and taking the natural logarithm, the above equation yields

$$
\ln \left(\frac{d X}{d t}\right)=\ln \left(A \cdot X^{n}\right)-\frac{E}{R T}=\ln (A)+n \ln X-\frac{E}{R}\left(\frac{1}{T}\right)
$$

Here, $A, n, T$, and $R$ represent the pre-exponential factor $\left(\mathrm{s}^{-1}\right)$, reaction order, pyrolysis temperature $(\mathrm{K})$, and gas constant (8.314 $\mathrm{J} / \mathrm{mol}^{-1} \mathrm{~K}^{-1}$ ), respectively.

The activation energy, $E(\mathrm{~kJ} / \mathrm{mol})$, based on Eq. (9), can be determined from the slope of $-\mathrm{E} / \mathrm{R}$ based on a plot of $1 / \mathrm{T}$ vs $\ln (d X / d t)$. The intercept $\ln \left(A X^{n}\right)$ was obtained from Eq. (9) for each conversion, from 10 to $90 \%$. The pre-exponential factor (A) could be obtained by assuming that the order of reaction $(n)$ is 0,1 , or 2 [17]. Table 2 shows that the activation energies had similar values of 67.0, 71.9, and $81.7 \mathrm{~kJ} \mathrm{~mol}^{-1}$ at conversions of 10,20 and $30 \%$, respectively, until a conversion of $40 \%$, where the activation energies increased to $101.7 \mathrm{~kJ} \mathrm{~mol}^{-1}$. This may be due to the decomposition of carbohydrates $[17,23]$. After that, the activation energy decreased slowly with a $40 \%$ to $70 \%$ increase in the conversions. When the conversions increased from $70 \%$ to $90 \%$, the activation energy increased sharply because of protein degradation [1, 17].

The results in this study are similar to those reported by $\mathrm{Li}$ et al. [7], where the activation energies and pre-exponential factors of sewage sludge were in the range of 59.6-150.3 kJ mol${ }^{-1}$ and $1.6 \times 10^{7}-6.0 \times 10^{11} \mathrm{~min}^{-1}$, respectively. When compared with the activation energy for the pyrolysis of palm fiber (192.7 to 689.0 $\mathrm{kJ} / \mathrm{mol}$ for the conversion of 10 to $90 \%$ ), SALSE could be degraded much more easily than palm fiber [24]. Table 2 shows the pre-exponential factors calculated from Eq. (9), assuming the reaction to be of the $0^{\text {th }}, 1^{\text {st }}$ or $2^{\text {nd }}$ order. The pre-exponential factors increased with an increase in the heating rate. Most of the decomposition occurred at the conversions from $20 \%$ to $80 \%$, where the pre-exponential factors were in the range of $10^{0}-10^{5} \mathrm{~s}^{-1}$.

\subsection{Pyrolysis of Sewage Sludge in a Micro-tubing Reactor under Various Conditions}

The effect of the temperature $\left(370,380\right.$, and $\left.390^{\circ} \mathrm{C}\right)$ and reaction time (1 to $5 \mathrm{~min}$ ) used for pyrolysis on the product yield was investigated. Fig. 3 shows the yield of bio-oil, gas, and char as a function of the pyrolysis conditions for SALSE. The yields of bio-oil and gaseous products were increased with an increase in the reaction temperature and reaction time. The bio-oil yield increased from 8.8 to $30.9 \%$ at $370^{\circ} \mathrm{C}$ from 1 to $5 \mathrm{~min}$ and increased to a maximum of 10.1 to $33.3 \%$ at $390^{\circ} \mathrm{C}$ from 1 to $5 \mathrm{~min}$. The
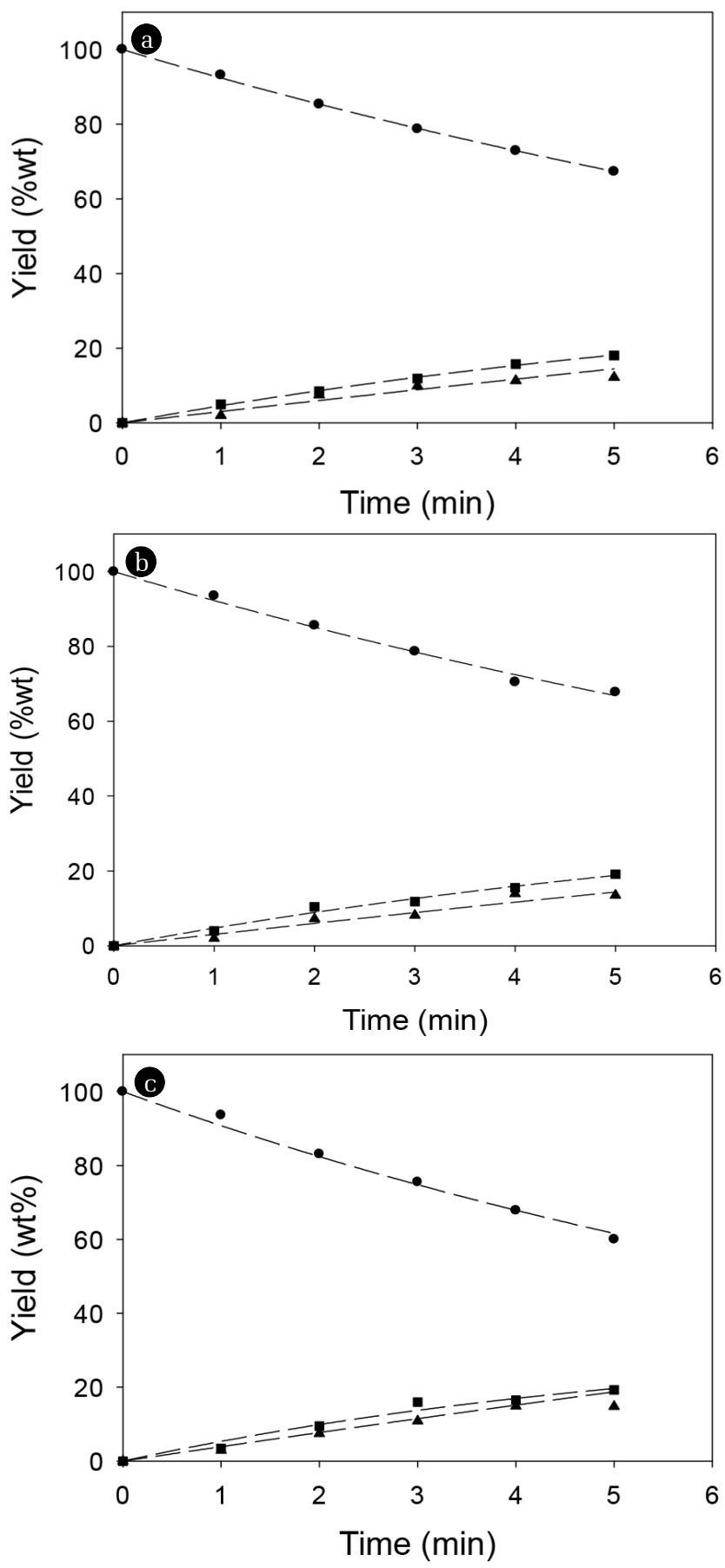

Fig. 3. Effect of reaction temperature and reaction time on the product yield of sewage sludge pyrolysis after lipid and sugar extraction. : solid yield, $\mathbf{\square}$; liquid yield, $\boldsymbol{\Delta}$; gas yield; (a) $370^{\circ} \mathrm{C}$, (b) $380^{\circ} \mathrm{C}$, (c) $390^{\circ} \mathrm{C}$. 
gas yield increased from 3.9 to $16.6 \%$ at $370^{\circ} \mathrm{C}$ from 1 to $5 \mathrm{~min}$ and increased to a maximum of 2.48 to $17.7 \%$ at $390^{\circ} \mathrm{C}$ from 1 to $5 \mathrm{~min}$. The higher bio-oil yield at higher temperatures is mainly attributed to the enhancement of devolatilization reactions at higher temperatures, because of more energy being available to break the bonds of organic compounds in the sludge [33]. However, the proportion of solids decreased with an increase in the reaction temperature and reaction time. The char yield of SALSE was decreased from 100 to $56.0 \%$ at a reaction temperature of $390^{\circ} \mathrm{C}$ and reaction time of $5 \mathrm{~min}$, while a char yield of $87.3 \%$ was obtained at $370^{\circ} \mathrm{C}$ in $1 \mathrm{~min}$.

\subsubsection{Kinetics model for pyrolysis of sewage sludge in the mi- cro-tubing reactor}

The data from the previous experiment that used a micro-tubing reactor were utilized to investigate the pyrolysis mechanism of SALSE using the three-lump kinetic model [19, 24, 28]. In this model, the pyrolysis mechanism was established with three assumptions; (1) reaction pathway is comprised of series and parallel reactions (2) the reactions are irreversible and first-order (3) sewage sludge is converted directly to gas, or converted to bio-oil and subsequently to gas. Accordingly, the mechanism of the pyrolysis of SALSE can be depicted as follows.

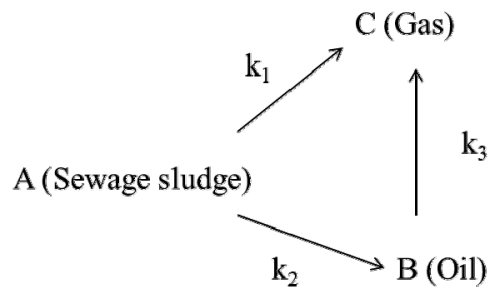

Here, $k_{1}, k_{2}$, and $k_{3}$ are the reaction rate constants for conversions of SALSE to gas, SALSE to bio-oil, and bio-oil to gas, respectively. Based on this mechanism, the kinetic equations for the reaction in terms of their yields $\left(C_{A}, C_{B}\right.$, and $\left.C_{C}\right)$ are as follows:

$$
\begin{aligned}
& -\frac{d C_{A}}{d t}=k_{1} C_{A}+k_{2} C_{A} \\
& \frac{d C_{B}}{d t}=k_{2} C_{A}-k_{3} C_{B} \\
& \frac{d C_{C}}{d t}=k_{1} C_{A}+k_{3} C_{B}
\end{aligned}
$$

Here, $C_{A}, C_{B}$, and $C_{C}$ are the yields of char (solid), bio-oil, and gas, respectively. These differential equations are solved to yield Eq. (12) to (14).

$$
\begin{gathered}
C_{A}=C_{A_{0}} \exp \left[-\left(k_{1}+k_{2}\right) t\right] \\
C_{B}=C_{B_{0}} e^{-k_{3} t}+k_{2} C_{A_{0}}\left(\frac{\exp \left[-\left(k_{1}+k_{2}\right) t\right]}{k_{3}-\left(k_{1}+k_{2}\right)}-\frac{\exp \left(-k_{3} t\right)}{k_{3}-\left(k_{1}+k_{2}\right)}\right)
\end{gathered}
$$

$$
C_{C}=C_{A_{0}}-C_{A}-C_{B_{0}}-C_{B}
$$

Here, $C_{A 0}$ and $C_{B 0}$ are the initial yields of solid (100\%) and bio-oil ( $0 \%$ ). The reaction rate constants $k_{1}, k_{2}$, and $k_{3}$ were obtained for each component product at three different reaction temperatures. The estimated reaction rate constants for the pyrolysis of SALSE are shown in Table 3 . The reaction rate constants of $k_{1}$ and $k_{2}$ increased from 0.0215 to $0.0318 \mathrm{~min}^{-1}$ and from 0.0990 to 0.1054 $\mathrm{min}^{-1}$, respectively, with an increase in the reaction temperature from $370^{\circ} \mathrm{C}$ to $390^{\circ} \mathrm{C}$, while $k_{3}$ decreased from 0.0601 to 0.0541 $\min ^{-1}$.

Table 3. Effect of Temperature on Reaction Rate Constants for the Pyrolysis of Residual Sewage Sludge after Lipid and Carbohydrate Extraction

\begin{tabular}{cccc}
\hline Temperature & \multicolumn{3}{c}{ Rate constant $\left(\mathbf{m i n}^{-1}\right)$} \\
\cline { 2 - 4 }$\left({ }^{\circ} \mathbf{C}\right)$ & $\boldsymbol{k}_{\mathbf{1}}$ & $\boldsymbol{k}_{\mathbf{2}}$ & $\boldsymbol{k}_{\mathbf{3}}$ \\
\hline 370 & 0.0215 & 0.0990 & 0.0601 \\
380 & 0.0248 & 0.1046 & 0.0985 \\
390 & 0.0318 & 0.1054 & 0.0541 \\
\hline
\end{tabular}

The decrease in $k_{3}$ may be due to the high pressure, caused by the high temperature [17]. As shown in Table 4, the reaction rate constants were in the order of $k_{2}>k_{3}>k_{1}\left(0.0318 \mathrm{~min}^{-1}\right)$ at each experimental temperature. These results indicate that the predominant reaction pathway of the pyrolysis of sludge after lipid and sugar extraction was from sewage sludge to bio-oil and bio-oil to gas, rather than from sewage sludge to gas [19].

\subsubsection{Bio-oil composition}

Bio-oil can be used as a source of chemicals as well as fuels [34]. Therefore, it is important to analyze the components of bio-oil. The bio-oil obtained from pyrolysis at the optimal temperature and duration of $390^{\circ} \mathrm{C}$ and $5 \mathrm{~min}$ in a micro-tubing reactor was analyzed by GC-MS, as shown in Table 4. The main components of bio-oil were trans-2-pentenoic acid (28.4\%), 2-methyl-2-pentenoic acid (12.3\%), tetradecane nitrile (6.5\%), and 4-methyl-phenol (5.1\%), and these four components accounted for $52.3 \%$ of the bio-oil. These results show that oxygenated compounds such as acids, ketones, and phenols are formed by the pyrolysis of lipids and polysaccharides in the sewage sludge. Furthermore, nitrogen compounds such as nitriles and amides are formed by the pyrolysis of the protein and nucleic acid in the sewage sludge derived from dead microorganisms [35-36]. As stated above, the bio-oil composition of sewage sludge in this study was a complex mixture. It could be grouped into the following classes: aliphatic hydrocarbons (tridecane, pentadecane and hexadecane, etc.), aromatics (cyclotetradecane and cyclododecane), phenols (phenol and 4-methyl-phenol), ketones (4-piperidinone), acids (2-butenoic acid and trans-2-pentenoic acid), and nitrogen (tetradecanenitrile) compounds, which were similar to the classes of sewage sludge, described by Ma et al. [21], Arazo et al. [35], and Lin et al. [37]. A high proportion of aliphatic hydrocarbons would be favorable for fuel-related applications [38] because straight chain hydrocarbons have a high heating value and lower viscosity. These are 
Table 4. Composition of Bio-oil Produced by Pyrolysis of Residual Sewage Sludge $\left(390^{\circ} \mathrm{C}\right.$ for 5 min)

\begin{tabular}{|c|c|c|c|}
\hline RT & Area (\%) & Compositions & Structure \\
\hline 7.375 & 1.3 & 2-Butenoic acid & \\
\hline 11.087 & 28.4 & trans-2-Pentenoic acid & \\
\hline 12.319 & 4.8 & Octamethyl cyclotetra siloxane & \\
\hline 13.430 & 12.3 & 2-Methyl-2-pentenoic acid & \\
\hline 14.963 & 5.1 & 4-methyl-Phenol & \\
\hline 15.178 & 1.4 & Phenol & \\
\hline 15.867 & 4.7 & 4-Piperidinone & \\
\hline 21.121 & 4.2 & 1-Tridecene & \\
\hline 21.345 & 2.3 & Tridecane & \\
\hline 23.774 & 1.9 & Cyclododecane & \\
\hline 23.989 & 2.0 & Tetradecane & \\
\hline 26.280 & 2.4 & 1-Pentadecene & \\
\hline 26.469 & 4.3 & Pentadecane & \\
\hline 27.796 & 2.6 & Cyclotetradecane & \\
\hline 28.640 & 4.2 & 1-Hexadecene & \\
\hline 28.821 & 3.5 & Hexadecane & \\
\hline 30.543 & 3.4 & 1-Heptadecene & \\
\hline 30.681 & 1.6 & (8E)-8-Heptadecene & \\
\hline 30.905 & 6.5 & Tetradecanenitrile & \\
\hline 31.043 & 3.1 & Heptadecane & \\
\hline
\end{tabular}


important properties of fuels used in transport and stationary engines [39]. In addition, Fonts et al. [40] reported that a high proportion of aliphatic hydrocarbons would enable the use of pyrolysis liquid as fuels.

\section{Conclusions}

To achieve the utilization of the entire sewage sludge that remains after lipid and sugar extraction, it was used to produce bio-oil. The lipid and carbohydrate content was decreased significantly from 14.5 to $2.3 \%$ and 8.9 to $1.0 \%$, respectively after lipid and sugar extraction. The pyrolysis of sludge in TGA mainly occurred at temperatures lower than $400^{\circ} \mathrm{C}$. Therefore, the pyrolysis of sewage sludge after lipid and sugar extraction was carried out in a micro-tubing reactor at 370,380 , and $390^{\circ} \mathrm{C}$ at different reaction time durations of 1 to $5 \mathrm{~min}$. The maximum bio-oil and gas yields of $33.3 \%$ and $17.7 \%$ were obtained after pyrolysis at $390^{\circ} \mathrm{C}$ for $5 \mathrm{~min}$, while the solid yield decreased from 100 to $56.0 \%$. The kinetic rate constants indicated that the predominant reaction pathways for the pyrolysis of SALSE are from sewage sludge to bio-oil, and subsequently to gas, rather than from sewage sludge to gas. The main components of bio-oil were trans-2-pentenoic acid (28.4\%), 2-methyl-2-pentenoic acid (12.3\%), tetradecane nitrile (6.5\%), and 4-methyl-phenol (5.1\%).

We tried to produce bio-oil through pyrolysis from sewage sludge remaining after biodiesel and bioethanol production. Therefore, this study would maximize the utilization of solid waste and minimize its remnants in sewage sludge. However, pyrolysis requires a lot of energy and economic feasibility analysis should be performed in the future.

\section{Acknowledgments}

This research was supported by the Korea Sea Grant Program (Gang Won Sea Grant) funded by the Ministry of Oceans and Fisheries in Korea and the Basic Science Research Program through the National Research Foundation of Korea (NRF) funded by the Ministry of Education (NRF-2015R1D1A1A01060540). The authors greatly appreciate these supports.

\section{References}

1. Wang X, Zhao B, Yang X. Co-pyrolysis of microalgae and sewage sludge: Biocrude assessment and char yield prediction. Energy Conver. Manage. 2016;117:326-334.

2. Dufreche S, Hernandez R, French T, Sparks D, Zappi M, Alley E. Extraction of lipids from municipal wastewater plant microorganisms for production of biodiesel. J. Am. Oil Chem. Soc. 2007;84:181-187.

3. Korea Ministry of Environment. 2030: The plan for reducing sewage sludge, and production and utilization of biogas. 2013.

4. Choi OK, Song JS, Cha DK, Lee JW. Biodiesel production from wet municipal sludge: Evaluation of in situ transesterification using xylene as a cosolvent. Bioresour. Technol. 2014;166:51-56.

5. Folgueras MB, Alonso M, Díaz RM. Influence of sewage sludge treatment on pyrolysis and combustion of dry sludge. Energy 2013;55:426-435.

6. Pansuwan S, Yeom SH. Optimization of a two-step biodiesel production process comprised of lipid extraction from blended sewage sludge and subsequent lipid transesterification. Biotechnol. Bioprocess Eng. 2016;21:551-560.

7. Li X, Li W, Wang G. Pyrolysis characteristics and kinetics of municipal sludge by thermogravimetry-fourier transform infrared analysis (TG-FTIR). Adv. Mater. Res. 2013;807:1169-1175.

8. Othman MR, Park YH, Ngo TA, Kim SS, Kim J, Lee KS. Thermogravimetric characteristics and pyrolysis kinetics of Giheung Respia sewage sludge. Korean J. Chem. Eng. 2010;27:163-167.

9. Sanchez ME, Menendez JA, Dominguez A, et al. Effect of pyrolysis temperature on the composition of the oils obtained from sewage sludge. Biomass Bioenerg. 2009;33:933-940.

10. Gasco G, Cueto MJ, Mendez A. The effect of acid treatment on the pyrolysis behavior of sewage sludges. J. Anal. Appl. Pyrol. 2007;80:496-501.

11. Pokorna E, Postelmans N, Jenicek P, Schreurs S, Carleer R, Yperman J. Study of bio-oils and solids from flash pyrolysis of sewage sludges. Fuel 2009;88:1344-1350.

12. Saleh TA, Sulaiman KO, AL-Hammadi SA, DafallaH, Danmaliki GI. Adsorptive desulfurization of thiophene, benzothiophene and dibenzothiophene over activated carbon manganese oxide nanocomposite: With column system evaluation. J. Clean. Prod. 2017;154:401-412.

13. Saleh TA, Al-Hammadi SA, Tanimu A, Alhooshani $K$. Ultra-deep adsorptive desulfurization of fuels on cobalt and molybdenum nanoparticles loaded on activated carbon derived from waste rubber. J. Colloid Interface Sci. 2018;513:779-787.

14. Saleh TA, Tuzen M, Sarı A. Magnetic activated carbon loaded with tungsten oxide nanoparticles for aluminum removal from waters. J. Environ. Chem. Eng. 2017;5:2853-2860.

15. Pansuwan S. Study on total utilization of sewage sludge to bio-fuel (Biodiesel, Bioethanol, Bio-oil) [dissertaion]. Gangneung: Gangneung-Wonju National Univ.; August 2017.

16. Dubois M, Gilles KA, Hamilton JK, Rebers PA, Smith F. Colorimetric method for determination of sugars and related substance. Anal. Chem. 1956;28:350-356.

17. Kim SS, Ly HV, Kim J, Lee EY, Woo HC. Pyrolysis of microalgae residual biomass derived from Dunaliella tertiolecta after lipid extraction and carbohydrate saccharification. Chem. Eng. J. 2015;263:194-199.

18. Ly HV, Kim SS, Kim J, Choi JH, Woo HC. Effect of acid washing on pyrolysis of Cladophora socialis alga in microtubing reactor. Energy Convers. Manage. 2015;106:260-267.

19. Vo TK, Ly HV, Lee OK, et al. Pyrolysis characteristics and kinetics of microalgal Aurantiochytrium sp. KRS101. Energy 2017;118:369-376.

20. Demirbas A. Calculation of higher heating values of biomass fuels. Fuel 1997;76:431-434.

21. Ma W, Du G, Li J, et al. Supercritical water pyrolysis of sewage sludge. Waste Manage. 2017;59:371-378.

22. Calvo LF, Otero M, Jenkins BM, Garcıa AI, Moran A. Heating 
process characteristics and kinetics of sewage sludge in different atmospheres. Thermochim. Acta 2004;409:127-135.

23. Kim SS, Ly HV, Choi GH, Kim J, Woo HC. Pyrolysis characteristics and kinetics of the alga Saccharina japonica. Bioresour. Technol. 2012;123:445-451.

24. Ly HV, Kim J, Kim SS. Pyrolysis characteristics and kinetics of palm fiber in a closed reactor. Renew. Energ. 2013;54:91-95.

25. Cao JP, Li LY, Morishita K, et al. Nitrogen transformations during fast pyrolysis of sewage sludge Jing-Pei. Fuel 2013;104:1-6.

26. Huang X, Cao JP, Shi P, et al. Influences of pyrolysis conditions in the production and chemical composition of the bio-oils from fast pyrolysis of sewage sludge. J. Anal. Appl. Pyrol. 2014;110:353-362.

27. Zhang J, Tiana Y, Zhu J, Zuo W, Yin L. Characterization of nitrogen transformation during microwave-induced pyrolysis of sewage sludge. J. Anal. Appl. Pyrol. 2014;105:335-341.

28. Park YH, Kim J, Kim SS, Park YK. Pyrolysis characteristics and kinetics of oak trees using thermogravimetric analyzer and micro-tubing reactor. Bioresour. Technol. 2009;100:400-405.

29. Li M, Xiao B, Wang X, Liu J. Consequences of sludge composition on combustion performance derived from thermogravimetry analysis. Waste Manage. 2015;35:141-147.

30. Magdziarz A, Werle S. Analysis of the combustion and pyrolysis of dried sewage sludge by TGA and MS. Waste Manage. 2014;34:174-179.

31. Shao J, Yan R, Chen H, Wang B, Lee DH, Liang DT. Pyrolysis characteristics and kinetics of sewage sludge by thermogravimetry Fourier transform infrared analysis. Energ. Fuel. 2007;22:38-45.
32. Singh RK, Bijayani B, Sachin K. Determination of activation energy from pyrolysis of paper cup waste using thermogravimetric analysis. Res. J. Recent Sci. 2012;2:177-182.

33. Alvarez J, Lopez G, Amutio M, et al. Characterization of the bio-oil obtained by fast pyrolysis of sewage sludge in a conical spouted bed reactor. Fuel Process. Technol. 2016;149:169-175.

34. Fonts I, Azuzrz M, Gea G, Murillo MB. Study of the pyrolysis liquids obtained from different sewage sludge. J. Anal. Appl. Pyrol. 2009;85:184-191.

35. Arazo RO, Genuino DAD, Mark DGL, Sergio CC. Bio-oil production from dry sewage sludge by fast pyrolysis in an electrically-heated fluidized bed reactor. Sust. Environ. Res. 2017;27:7-14.

36. Alvarez, J, Amutio M, Lopez G, Bilbao J, Olazar M. Fast co-pyrolysis of sewage sludge and lignocellulosic biomass in a conical spouted bed reactor. Fuel 2015;159:810-818.

37. Lin Q, Chen G, Liu Y. Scale-up of microwave heating process for the production of bio-oil from sewage sludge. J. Anal. Appl. Pyrol. 2012;94:114-119.

38. Maher KD, Bressler DC. Pyrolysis of triglyceride materials for the production of renewable fuels and chemicals. Bioresour. Technol. 2007;98:2351-2368.

39. Shen L, Zhang DK. An experimental study of oil recovery from sewage sludge by low-temperature pyrolysis in a fluidised-bed. Fuel 2003;82:465-472.

40. Fonts I, Gea G, Azuara M, Abrego J, Arauzo J. Sewage sludge pyrolysis for liquid production: A review. Renew. Sust. Energ. Rev. 2012;16:2781-2805. 